\title{
Refractometric Study of 2-Chloro-4-Amino Phenol In Ethanol-Water Systems
}

\author{
Dattaram P.Goswami \\ Department of Chemistry, Government Vidarbha Institute of Science and Humanities, Amravati (M.S.) PIN 444 \\ 604 India.
}

\begin{abstract}
Recently in this laboratory the refractometric study of 2-chloro-4-amino phenol was studied at various percentage compositions of solvents to investigate the effect of structure of 2-chloro-4-amino phenol in various percentage compositions. The data and results obtained during this study give the effect of ethanol and water in the ethanol-water system.
\end{abstract}

Key Words: 2-Chloro-4-amino phenol, ethanol-water percentage compositions, refractometry study

\section{Introduction}

Pharmaceutical, medicinal and biochemical literature survey showed that amino, chloro and phenol nucleus containing drugs produced their identity in medicinal, agricultural and pharmaceutical chemistry. Most of them are used as muscle relaxant ${ }^{1}$, hypoglycemic agent ${ }^{2}$, blood pressure depressant ${ }^{3}$, anti diabetic drugs ${ }^{4}$. They showed anti-tumor properties ${ }^{6}$ anti-bacterial ${ }^{7-9}$, anti-inflametory ${ }^{10}$ and anti-cancer properties ${ }^{11}$. These drugs are also used as hormone antagonists ${ }^{12}$ and antipsychotic agent ${ }^{13}$ in industries they are also used as finishing and brightening agents ${ }^{14}$. In agricultural field they are used as herbicidals ${ }^{15-23}$, sea water, algicidals ${ }^{24}$, fungicidal ${ }^{25}$ insecticidal and pesticidal ${ }^{26}$. Hence, these compounds obtained the new branches of development in the medicinal, pharmaceuticals, agricultural and biochemical fields. The drug absorption, transmission, activity and effect will directly predicted by the refractometric measurement of the solute (drug) and solvent in the human anatomy. This information is essential for deciding dose of drug to the patient. Result of refractometric measurement directly gives information regarding solute-solvent interactions. This study is an important tool for pharmaceutical and medicinal sciences. Taking all these things into consideration, it was thought interesting to carry out the refractometric measurement of 2-chloro-4-amino phenol. This study explores the potency of 2-chloro-4-amino phenol, stability of a drug and also to renovate and modify the traditional drugs which are used by medicinal practitioner. One of the unique and important properties of liquid is refractive index. When a ray of light passes from less dense to denser medium then there is change in the direction of refraction and angle of refraction changes and ultimately the refractive index get changed. The result obtained during this investigation directly through light on the dipole association of 2-chloro-4-amino phenol, and mutual compensation of dipoles these results are much more useful for transmission, stability, activity and effect of drug hence this study is essential. From this point of view the present investigation was carried out 2-chloro-4amino phenol in ethanol-water system at various percentage compositions. This is hither to unknown. This study becomes milestone in drug, medicinal, pharmaceutical of 2-chloro-4-amino phenol molecule.

\section{Experimental}

The $0.1 \mathrm{M}$ solution of 2-chloro-4-amino phenol in different percentage of ethanol- water at different concentration of 2-chloro-4-amino phenol ( $0.1 \mathrm{M}, 0.075 \mathrm{M}, 0.056 \mathrm{M}, 0.042 \mathrm{M})$ in $60 \%, 70 \%$ and $80 \%$ ethanolwater mixture were prepared .All weighing was made on Mechaniki Zaktady Precyzying Gdansk Balance [ Poland make $( \pm 0.001 \mathrm{gm})]$. The densities of the solutions were determined by a bicapillary pyknometer $( \pm 0.2 \%$ ) having a bulb volume of about $10 \mathrm{~cm}^{3}$ and capillary having an internal diameter of $1 \mathrm{~mm}$. The refractive indices of solvent mixture and solutions were measured by Abbe's refractometer $( \pm 0.001)$. The temperature of prism box was maintained at $29^{\circ} \mathrm{C}$. Initially, the refractometer was calibrated with glass piece $(n=1.5220)$ provided with the instrument.

\section{Observation and calculation}

The present work deals with the study of molar refraction and polarizability constant of 2-chloro-4amino phenol in 60\% ethanol-water , 70\% ethanol-water and $80 \%$ ethanol-water mixture of different composition at $302^{0} \mathrm{~K}\left(29^{\circ} \mathrm{C}\right)$. The data obtained have been used to compute intermolecular interaction. The refractometric reading were taken as described in literature. 


\section{Result and Discussion}

The molar refraction of solution of 2-chloro-4-amino phenol in ethanol-water mixture were determined by a following equation,

$$
R_{m}=\frac{\left(n^{2}-1\right)}{\left(n^{2}+2\right)}\left\{\frac{\left[x_{1} m_{1}+x_{2} m_{2}+x_{3} m_{3}\right]}{d}\right\}
$$

Where

$\eta$ is refractive index of solution

$\mathrm{X}_{1}$ is mole function of ethanol

$\mathrm{X}_{2}$ is mole function of water

$\mathrm{M}_{1}, \mathrm{M}_{2}$, and $\mathrm{M}_{3}$ are molecular weights of ethanol,water and solute respectively

$\mathrm{d}$ is density of solution

The molar refraction of 2-chloro-4-amino phenol is calculated as

$\mathrm{R}_{\text {lig }}=\mathrm{R}_{\text {mixture }}-\mathrm{R}_{\text {Ethanol-water }}$

Where

$\mathrm{R}_{\text {Ethanol-water }}$ - The molar refraction of solvent Ethanol-Water mixture

The polarizability constant $(\alpha)$ of 2-chloro-4-amino phenol iscalculated from the following relation

Where No is Avogadro's number

$$
R_{\text {Ig }}=\frac{4}{3} \pi N b \alpha
$$

Table No 1: Molar refraction of different percentage of ethanol-water mixture

\begin{tabular}{|c|c|}
\hline \% of Ethanol-Water Mixture & Molar Refraction (RM) $\left(\mathbf{c m}^{\mathbf{3}} \mathbf{m o l e}^{\mathbf{- 1}}\right)$ \\
\hline 100 & 22.5187 \\
\hline 90 & 16.3794 \\
\hline 80 & 12.86 \\
\hline 70 & 12.5764 \\
\hline 60 & 10.9761 \\
\hline
\end{tabular}

A ] Molar refraction and polarizability constant at different concentration for 2-chloro-4-amino phenol

TableNo:2 System: 60\% Ethanol-Water

Temp: $29 \pm 0.1^{0} \mathrm{C}$

\begin{tabular}{|c|c|c|c|c|c|}
\hline Concentration & Density $\mathbf{P} \times \mathbf{1 0}^{\mathbf{3}}$ & Refractive Index & $\mathbf{R}_{\text {mix }}$ & $\mathbf{R}_{\text {lig }}$ & $\alpha \mathbf{x 1 0} \mathbf{- 2 3}^{\mathbf{2 3}}$ \\
\hline $\mathbf{C}(\mathbf{M})$ & $\left(\mathbf{K g}-\mathbf{m}^{\mathbf{4}}\right)$ & $(\eta)$ & $\left(\mathbf{M}^{\mathbf{3}} \mathbf{m o l e} \mathbf{l}^{\mathbf{1}}\right)$ & $\left(\mathbf{M}^{\mathbf{3}} \mathbf{m o l e} \mathbf{1}^{\mathbf{1}}\right)$ & $\left(\mathbf{C m}^{\mathbf{3}}\right)$ \\
\hline 0.1 & 1.256 & 1.5174 & 9.1992 & 0.5764 & 0.0249 \\
\hline 0.075 & 1.2558 & 1.5134 & 9.1512 & 0.5273 & 0.02232 \\
\hline 0.056 & 1.2555 & 1.5119 & 9.1096 & 0.4857 & 0.02067 \\
\hline 0.042 & 1.2552 & 1.5122 & 9.1059 & 0.492 & 0.02052 \\
\hline
\end{tabular}

\begin{tabular}{|c|c|c|c|c|c|}
\hline $\begin{array}{c}\text { Concentration } \\
\text { C(M) }\end{array}$ & $\begin{array}{c}\text { Density P×10 } \\
\left(\mathrm{Kg}-\mathrm{m}^{4}\right)\end{array}$ & $\begin{array}{c}\text { Refractive Index } \\
(\eta)\end{array}$ & $\begin{array}{c}\mathbf{R}_{\text {mix }} \\
\left(\mathbf{M}^{3} \text { mole }^{\mathbf{1}}\right)\end{array}$ & $\begin{array}{c}\mathbf{R}_{\text {lig }} \\
\left(\mathbf{M}^{3} \text { mole }^{1}\right)\end{array}$ & $\begin{array}{c}\alpha \times 10^{-23} \\
\left(\mathrm{Cm}^{3}\right)\end{array}$ \\
\hline 0.1 & 1.0295 & 1.4054 & 9.9868 & 0.3304 & 0.01568 \\
\hline 0.075 & 1.0303 & 1.4042 & 9.9172 & 0.2608 & 0.01263 \\
\hline 0.056 & 1.0293 & 1.4034 & 9.8683 & 0.2119 & 0.01069 \\
\hline 0.042 & 1.0281 & 1.4423 & 9.8296 & 0.1735 & 0.00916 \\
\hline
\end{tabular}

Table No : 3 System: 70\% Ethanol-Water

\begin{tabular}{|c|c|c|c|c|c|}
\hline $\begin{array}{c}\text { Concentration } \\
\text { C(M) }\end{array}$ & $\begin{array}{c}\text { Density P×10 } \\
\left(\mathrm{Kg}^{3}-\mathrm{m}^{4}\right)\end{array}$ & $\begin{array}{c}\text { Refractive Index } \\
(\eta)\end{array}$ & $\begin{array}{c}\mathbf{R}_{\operatorname{mix}} \\
\left(\mathbf{M}^{3} \mathbf{m o l e}^{1}\right)\end{array}$ & $\begin{array}{c}\mathbf{R}_{\text {lig }} \\
\left(\mathbf{M}^{3} \mathbf{m o l e}^{1}\right)\end{array}$ & $\begin{array}{c}\alpha \times 10^{-23} \\
\left(\mathbf{C m}^{3}\right)\end{array}$ \\
\hline 0.1 & 1.0347 & 1.4121 & 12.2674 & 0.3284 & 0.01636 \\
\hline 0.075 & 1.0326 & 1.4113 & 12.2116 & 0.2726 & 0.01415 \\
\hline 0.056 & 1.0314 & 1.4105 & 12.1616 & 0.2181 & 0.01199 \\
\hline 0.042 & 1.0298 & 1.4093 & 12.1094 & 0.1704 & 0.01011 \\
\hline
\end{tabular}

Table No: 4 System: 80\% Ethanol-Water

The values of molar refraction of ethanol-Water mixture were presented in the Table No 1 . The values of molar refraction and polarizabolity constant at different concentration of 2-chloro-4-amino phenol in $60 \%$, $70 \%$ and $80 \%$ of Ethanol-Water mixture were given in Table No 2 to 4 . It was observed form these tables that the molar refraction and polarizabolity constant of 2-chloro-4-amino phenol decreases in the concentration of 2chloro-4-amino phenol .

From the data it can be predicted that, when the percentage of ethanol increases, molar refractivity (true molar volume) continuously increases. At the same time polarizabolity constant of a 2-chloro-4-amino phenol decreases. This may be attributed that with the increase in percentage of ethanol it causes decreases in dielectric 
constant of medium and also considerable dipole association (intermolecular attraction) take place which can be accompanied by decrease in polarisability. It was observed from Table No. 2-4 when concentration of ethanol increase the refractive index also increase for 2-chloro-4-amino phenol..More detail physical, biochemical, and medicinal study is required on 2-chloro-4-amino phenol.

From this study it is clear that when the percentage of ethanol increases the solute solvent interactions i.e. interaction of 2-chloro-4-amino phenol and ethanol increases which may stabilize the drug activity of higher percentage of ethanol. From this it can be concluded that the drug absorption, drug transmission and drug effect of 2-chloro-4-amino phenol is more effective at higher concentration of ethanol

\section{References}

[1]. Dandia A , Arya K, Sati M ,Synthetic Communication, 34(6) , 1141 (2004)

[2]. Nitha B, Stayo De, Adikari S.K, Devasagayam T. P.H. And Janardhan K, Pharmaceutical Biology, 48 (4), 453 (2010)

[3]. Yang J.J., Yang Z., and Zhang T., Tuxicology in Vitro 24(2), 397(2010)

[4]. Gorinstein, Nijaman K, Park Y.S., Heo B.G., Cho J.Y. , and Bae J.H. , Food Control 20(4), 407(2009)

[5]. Seczewski F., and Bulakowska A. European J. Medicinal Chemistry 41(5), 611(2006)

[6]. Kruth F., Dalise H.M., Ruttinger H.H., and Erobberg P., Bioorganic and Medicinal Chem., 18(5),1816 (2010)

[7]. Gang Cheng, NirShapir, Micheal J., Sadowsky, and Lawrence P., Wackett, Applied and Environmental Microbiology 71(8), 4437(2005)

[8]. Vicente Garcia-Gonzalez, Fernando Govantes ,Odil Porrua , and Eduardo Santero , J. Bacteriology 187(1), 155(2005)

[9]. Srinivas K., Srinivas W., Bhanuprakash K., Harikishor K., Murty U.S.N.and Jayatirtha Rao V., Europea J.Medicinal Chem. 41(11), $1240(2006)$

[10]. Adibily A.O., Koekemoer T., Adibily A.P., and Smith N., Pharmaceutical Biology 47(4), 320(2009)

[11]. Paquin Isabelle, Lu Aihua, Claude Marie and Delcome Daniel , Bioorganic and Medicinal Chem.Lett., 18(3), 1067(2008)

[12]. PontilloJoeseph, GuoZhiqiang, Wu Dongpei, Scott R. Struthers, and Chen Chem, Bioorganic and Medicinal Chem Litt . 15(19), 4363 (2005).

[13]. Frankenburg Frances R., and baldessanini Ross J., Harverd Review of Psychiatry 16(15), 299(2008)

[14]. MansoonIqbalScribd Textile Dyes , 76, 231 (2008)

[15]. Sanchez M., Garbi C., Martinez-Alvarez R. , Ortiz I.T., Allende J.L., and Martin M., Applied Microbiology and Biochemistry , 66(5), 589 (2005)

[16]. Marcacci Sylvie, Reveton Muriel, Revanel Patrick and Schwitzguebel Jean-Paul, Environmental and Botany 56(2), 205 (2006)

[17]. Trimble A.J., and Lydy M.J., Archives of Environmental and Experimental Contamination and Toxicity 51(1), 29 (2006)

[18]. Sergeyeva T.A., Brovko O.O.,Piletska E.V., Piletsky S.A., Goncharova L. A. and Elskaya A.V., Analytic Chimica Acta 582(2), $311(2007)$

[19]. Salmain M., Fischer-Durand N., and Pradier C.M. , Analytical Biochemistry 373(1),61(2008)

[20]. Herranz S. , Azoon J.R., Pena E.B., Maruzuela M.D., and Mereno- Bundi ., Analytical and Bioanalytical Chem., 391(5), 1801 (2008)

[21]. Hase Y., Talsuno M., Nishi T., Kotaoka k., Kabe Y., and Watanabe H., Biochemical and Biophysical Research Communication 366(1), 1 (2008)

[22]. Franek M., and Hruska K., Vet Medi-Czech , 50(1), 1 (2005)

[23]. Dolaptsogloy C., Karpouzas D.G., Spiroudi D.M., Eleftherohorinos I., and Voudrias E.A., J.Environ. Qual, 38 , 782 (2000)

[24]. Lam Ka Ho , Ph.D. Thesis Submitted to Hong Kong University (2000)

[25]. Oyawa N., Okamura H., Hiral H., and Nishida T., Chemosphere , 55(3), 487 (2004)

[26]. Piletska E.V., Turner N.W., Anthony P.F., Turner and Piletsky S.A., J. Controlled Release, 108(1), 132, (2005). 